\title{
JOINING THE COMBINATION OF AHSS STEEL AND HSLA STEEL BY RESISTANCE SPOT WELDING
}

\author{
L'uboš KAŠČÁK*, Emil SPIŠÁK*, Ivan GAJDOŠ*
}

${ }^{*}$ Faculty of Mechanical Engineering, Department of Technology and Materials, Technical University of Košice, Letná 9, 04200 Košice, Slovakia

lubos.kascak@tuke.sk, emil.spisak@tuke.sk, ivan.gajdos@tuke.sk

\begin{abstract}
The paper deals with the optimization of parameters of resistance spot welding and quality analysis of welded joints made by combination of galvanized Advanced High Strength Steel and High Strength Low Alloy steel. It is an advanced material combination utilized in automotive industry to reduce weight of the vehicle body and consequently lowering the fuel consumption to achieve the lowest possible fuel consumption, high active and passive safety of passengers while decreasing the amount of emission. The quality of welded joints was evaluated by destructive tests and non-destructive tests. The shear tensile test according to STN 051122 standard was used. Some samples were prepared for metallographic analysis, where the influence of the welding parameters on the structure of welded joint and occurrence of pores in the weld metal caused by evaporation of zinc from the coating was observed.
\end{abstract}

Key words: Car Body Sheets, Spot Welding, Tensile Test, Microhardness

\section{INTRODUCTION}

In resistance spot welding, the weld is made by a combination of heat, pressure and time. This technique is commonly used in automotive industry due to its high efficiency in manufacturing thin metal sheets. A wide variety of metal sheets up to $3 \mathrm{~mm}$ thickness can be handled by the resistance spot welding method (Sevim, 2006; Spišák et al., 2011). In the last decade a change in body shell mass production has occurred in the automotive industry. In answer to the intensifying energy crisis and in order to meet customer requirements for automobiles such as weight reduction for energy saving and enhancement of passenger safety, new materials, e.g. advanced high strength steels (AHSS) have to be applied (Brauser, 2010; Mucha et al., 2011). These materials are gaining in popularity due to their high strength in combination with good ductility characteristics compared to traditional high strength steels, for example micro-alloyed steels (Tumuluru, 2006). An important AHSS representative is the socalled TRIP (Transformation Induced Plasticity) steel dominated by a ferrite matrix with retained austenite, bainite and martensite as dispersed phases, offering excellent mechanical properties due to the transformation of retained austenite into martensite during plastic straining (Lacroix, 2008). As a result, both strength and uniform strain increase owing to the appearance of a harder phase and to the additional local plastic yielding of the surrounding grains related to the transformation strain as was described in (Saleh and Priestner, 2001). The TRIP effect, which is exhibited by such materials, is characterized by the phenomenon known as strain-induced martensitic transformation (SIMT). Due to the onset of plastic straining, the retained austenite undergoes SIMT which enhances the work hardenability of such steels due to the transformation of the austenite phase to the much harder martensite phase. This brings about a resistance to local necking which explains the uniform elongation and enhanced formability observed in such steels ( Sierra and Nemes, 2008).

The challenge of using the coated AHSS steels in the industry is that they are readily inclined to exhibit expulsion during the spot welding. As well, the presence of the coating results in the accel- erated degradation of the welding electrodes, leading to earlier expulsion and frequent replacement or re-dressing of the electrodes (Ma et al., 2008; Williams and Parker, 2004).

HSLA steel is well-known type of steel alloy that provides many benefits over regular steel alloys. In general, HSLA alloys are much stronger and tougher than ordinary plain carbon steels. HSLA steels are so called because they only contain a very small percentage of carbon. A typical HSLA steel may contain $0.15 \%$ carbon, $1.65 \%$ manganese and low levels (under 0.035\%) of phosphorous and sulphur. Most HSLA steels are furnished in the as-hot-rolled condition with ferritic-pearlitic microstructure. The exceptions are the controlled-rolled steels with an acicular ferrite microstructure and the dual-phase steels with martensite dispersed in a matrix of polygonal ferrite. These two types of HSLA steels use the formation of eutectoid structures for strengthening, while the ferritic-pearlitic HSLA steels generally require strengthening of the ferrite. Pearlite is generally an undesirable strengthening agent in structural steels because it reduces impact toughness and requires higher carbon contents. Moreover, yield strength is largely unaffected by a higher pearlite content. The ferrite in HSLA steels is typically strengthened by grain refinement, precipitation hardening, and, to a lesser extent, solidsolution strengthening. Grain refinement is the most desirable strengthening mechanism because it improves not only strength but also toughness (Gorni and Mei, 2004; Fernándes et al., 2007; Show et al., 2010).

More cracks and failures tend to occur around welds, in the heat affected zone (HAZ), because the joints are exposed to dynamic and static loads in the automobile structures. After spot wedling, important changes occur in mechanical and metallurgical properties of the spot welded areas and heat affected zones (Vural and Akkus, 2001). The investigation of these changes is very important for the safety strength of the welded joints. In some parts of the modern automobiles, galvanized AHSS steels sheets and HSLA steels sheets are joined together with resistance spot welding technique. The paper evaluates joints of combined materials made by resistance spot welding the materials utilized in automotive industry in car body production. 


\section{EXPERIMANTAL PROCEDURE}

The combination of dissimilar steel sheets were used for resistance spot welding: high strength low alloy steel H220PD with the thickness of $0.8 \mathrm{~mm}$ and advanced high strength steel TRIP $40 / 70+$ Z100MBO with the thickness of $0.77 \mathrm{~mm}$. Their basic mechanical properties and chemical composition are shown in Tab. 1 and Tab. 2.

Tab. 1. Basic mechanical properties of used steel sheets

\begin{tabular}{|c|c|c|c|c|}
\hline Material & $\begin{array}{c}\mathbf{R} p_{0.2} \\
{[\mathrm{MPa}]}\end{array}$ & $\mathbf{R}_{\mathbf{m}}[\mathrm{MPa}]$ & $\mathbf{A}_{\mathbf{8 0}}[\%]$ & $\mathbf{n}_{\mathbf{9 0}}$ \\
\hline H220PD & 238 & 382 & 36 & 0.228 \\
\hline TRIP40/70 & 450 & 766 & 26 & 0.278 \\
\hline
\end{tabular}

Tab. 2. Chemical composition (wt\%) of used steel sheets

\begin{tabular}{|c|c|c|c|c|c|c|}
\hline Material & $\mathbf{C}$ & $\mathbf{M n}$ & $\mathbf{S i}$ & $\mathbf{A l}$ & $\mathbf{C u}$ & $\mathbf{N i}$ \\
\hline H220PD & 0.012 & 0.435 & 0.119 & 0.041 & 0.040 & 0.013 \\
\hline TRIP40/70 & 0.141 & 1.627 & 0.185 & 1.986 & 0.053 & 0.016 \\
\hline Material & $\mathbf{C r}$ & $\mathbf{T i}$ & $\mathbf{V}$ & $\mathbf{N b}$ & $\mathbf{M o}$ & $\mathbf{P}$ \\
\hline H220PD & 0.046 & 0.033 & 0.012 & 0.052 & 0.009 & 0.057 \\
\hline TRIP40/70 & 0.056 & 0.007 & 0.017 & 0.037 & 0.024 & 0.046 \\
\hline
\end{tabular}

The following tests were performed for evaluation of joints' properties: tension test, microhardnesses test and a metallographical analysis. The samples with dimensions of $40 \times 90 \mathrm{~mm}$ and 30 $\mathrm{mm}$ lapping according to STN 051122 standard were used for the experiments (Fig. 1). Five samples were prepared for every combination of sheets. Resistance spot welding was carried out in laboratory conditions on a pneumatic spot welding-machine BPK 20 of VTS ELEKTRO Bratislava. $\mathrm{CuCr}$ welding electrodes were used according to ON 423039.71 standard. The diameter of working area of the electrode was $d=\varnothing 5 \mathrm{~mm}$.



Fig. 1. Dimensions of sample for tensile test

Tab. 3. Welding parameters (I-wedling current, Fz-pressing force, T-welding time

\begin{tabular}{|c|c|c|c|c|}
\hline $\begin{array}{c}\text { Marking } \\
\text { of sample }\end{array}$ & $\mathbf{I}[\mathbf{k A}]$ & $\mathbf{F z}[\mathbf{k N}]$ & $\mathbf{T}[\mathbf{p e r}]$. & $\begin{array}{c}\text { Weld diameter } \\
{[\mathrm{mm}]}\end{array}$ \\
\hline $\mathrm{A}_{5}$ & 5 & 6 & 10 & $\varnothing 5$ \\
\hline $\mathrm{A}_{6}$ & 6 & 6 & 10 & $\varnothing 5$ \\
\hline $\mathrm{A}_{7}$ & 7 & 6 & 10 & $\varnothing 5$ \\
\hline $\mathrm{A}_{8}$ & 8 & 6 & 10 & $\varnothing 5$ \\
\hline $\mathrm{A}_{9}$ & 9 & 6 & 10 & $\varnothing 5$ \\
\hline
\end{tabular}

The used parameters of resistance spot welding for each sample including pressing force of electrodes Fz, welding time $T$ and welding currents I are shown in Tab. 3. The samples were prepared by cutting against the direction of rolling. The surfaces of the samples were degreased in concentrated $\mathrm{CH} 3 \mathrm{COCH} 3$.

The welding current is the most important parameter in resistance welding which determines the heat generation by a power of square as shown in the formula. The size of the weld nugget increases rapidly with increasing welding current, but too high current will result in expulsions and electrode deteriorations. The amount of weld current is controlled by two things: first, the setting of the transformer tap switch determines the maximum amount of weld current available; second, the percent of current control determines the percent of the available current to be used for making the weld. Low percent current settings are not normally recommended as this may impair the quality of the weld. The weld current should be kept as low as possible. When determining the current to be used, the current is gradually increased until weld spatter occurs between the metal sheets (Zhang and Senkara, 2006).

The carrying capacities of the spot welded joints were evaluated according to standard STN 051122 - Tension test of spot welded joints. This test was used for measuring the maximum carrying capacities Fmax of the joints. The test was carried out on the metal strength testing machine TIRAtest 2300 produced by VEB TIW Rauenstein, with the loading speed of $8 \mathrm{~mm} / \mathrm{min}$.

Further tests for quality evaluation of spot welded joints included the metallographical analysis. The quality of welded joints was evaluated by light microscopy on metallographical scratch patterns prepared according to ISO 6507-1 and ISO 6507-2 standards on Olympus TH 4-200 microscope.

\section{RESULTS AND DISCUSSION}

The values of carrying capacity of welded joints were in the range from $5224 \mathrm{~N}$ to $7496 \mathrm{~N}$. Only one type of the joint occurs in all chosen parameters of welding - fusion welded joint. Measured values of carrying capacities of joints on welding current are shown in Fig. 2.

Dependency of carrying capacity of spot welds Fmax on welding current I can be expressed (calculation includes 5 samples for each current value):

$F \max =401.49 I+3491$

with coefficient of determination $\mathrm{R}^{2}=0,8829$

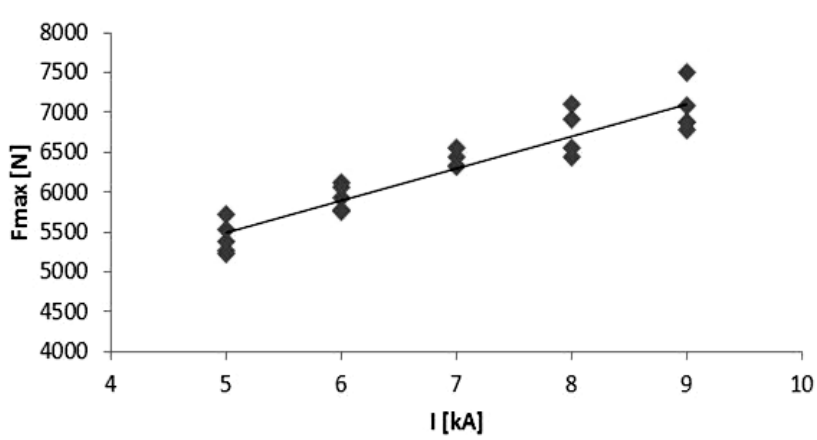

Fig. 2. Dependency of carrying capacities of spot welds Fmax [N] on welding current I [KA] 
Tensile tests were executed under displacement control conditions on the specimen configurations in order to characterise the static behaviour of the joints and to estimate the ultimate tensile strength. The maximum shearing load was the most significant value obtained from the "load-displacement" curves as shown in Fig. 3 as well as the corresponding displacement. The form of the curves indicates the behaviour of the joints under loading, especially capacity for deformation. The measured values of carrying capacities of the spot welds are shown in Tab. 4.



Fig. 3. Load-displacement curves and deformation of spot welded joints after tensile test

Tab. 3. Carrying capacities Fmax of the welds

\begin{tabular}{|c|c|c|c|c|c|}
\hline \multicolumn{7}{|c|}{ Fmax [N] } \\
\hline Sample No. & $\mathbf{A}_{\mathbf{5}}$ & $\mathbf{A}_{\mathbf{6}}$ & $\mathbf{A}_{\mathbf{7}}$ & $\mathbf{A}_{\mathbf{8}}$ & $\mathbf{A}_{\mathbf{9}}$ \\
\hline 1 & 5263 & 5922 & 6335 & 6919 & 6978 \\
\hline 2 & 5224 & 5763 & 6439 & 6758 & 7496 \\
\hline 3 & 5383 & 5771 & 6562 & 6835 & 6982 \\
\hline 4 & 5537 & 5921 & 6320 & 7098 & 6875 \\
\hline 5 & 5520 & 6052 & 6322 & 6893 & 7090 \\
\hline
\end{tabular}

The specimen failed partially through the periphery of the weld and partially through the base metal, which is confirmed in the failure mode of spot welded joints (Fig. 4) together with corresponding characteristic load vs. displacement curves generated in the experiments (Fig. 3). The carrying capacities of the samples are then influenced by the base metal strength.
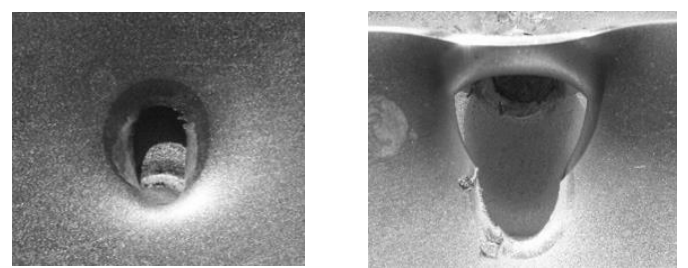

Fig. 4. Failures of spot welded joints of samples $A_{5}$ and $A_{9}$

Fig. 5 shows indentations formed by the welding electrodes. Changing the values of welding current influenced the welding electrode indentations on the surfaces of welded materials. The most obvious indentations were observed on the surfaces of samples prepared with the parameters of maximum value of welding current of $9 \mathrm{kA}$. The least obvious indentations were on the surfaces of both welded steels prepared with the minimum value of welding current of $5 \mathrm{kA}$.
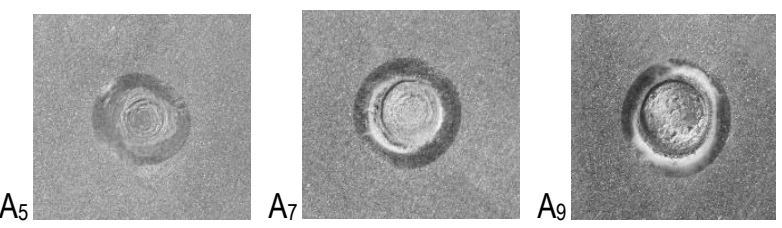

Fig. 5. Welding electrodes indentations of samples $A_{5}(I=5 \mathrm{kA})$, $A_{7}(I=7 \mathrm{kA})$ and $A_{9}(I=9 \mathrm{kA})$

The metallographical analysis confirmed formation of fusion welded joints with characteristic areas of weld metal (WM), heat affected zone (HAZ) and base material (BM). Figure 6 shows the macrostructures of spot welded joints of samples $A_{5}, A_{7}$ and Ag. The size of spot welds increased with increasing values of welding current. The sample $A_{5}$ welded with the lowest value of welding current $5 \mathrm{kA}$ shows the smallest weld nugget of all observed samples, with the narrow heat affected zone. The macrostructures of a weld joint show the solidification process of weld metal with a characteristic dendrite structure typical for resistance spot welds. The microscopic observation of macrostructures of the welds shows no pores and cavities occurring in the weld metal. The bigger weld nugget was observed in samples $A_{7}$, welded with the current of $7 \mathrm{kA}$. No pores and cavities occurring in the weld metal.
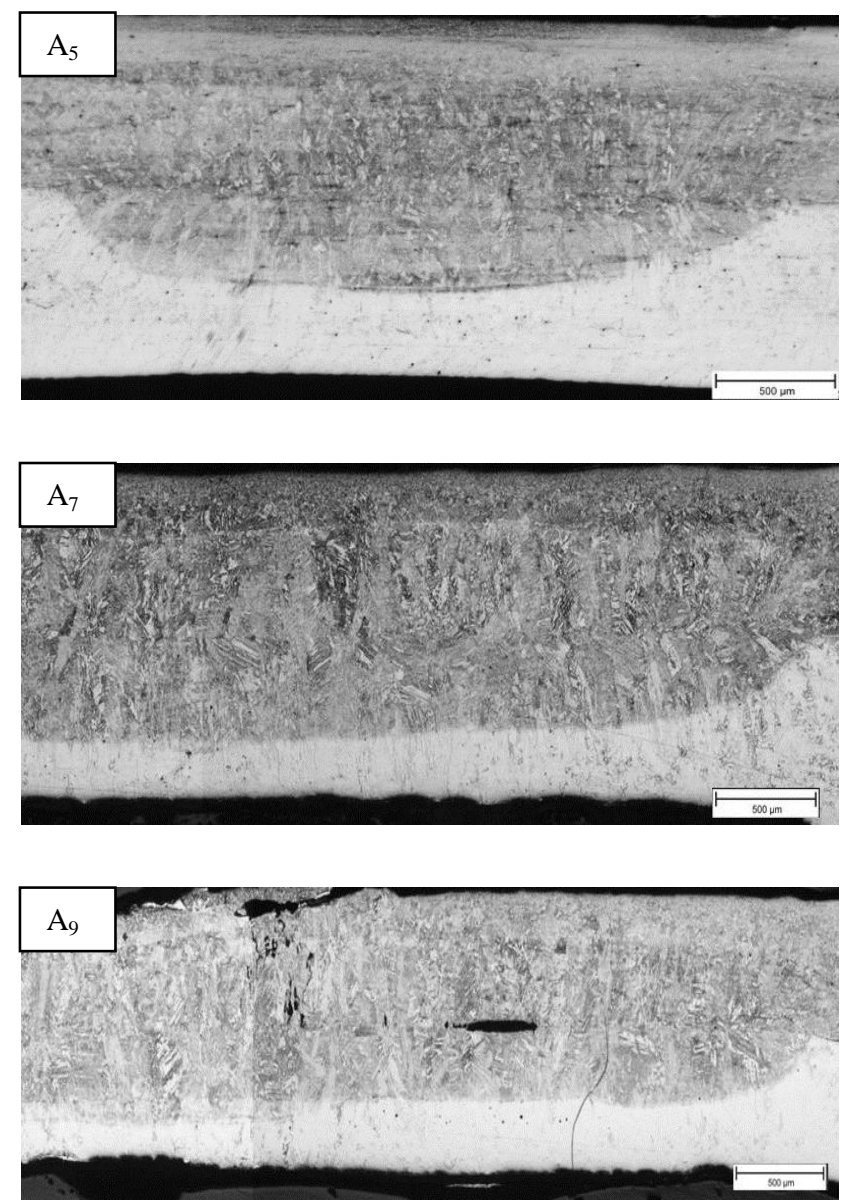

Fig. 6. Microstructures of the samples $A_{5}, A_{7}$ and $A_{9}$

The microstructure of weld metal consists of mostly finegrained martensite arranged in typical lamellar formations form the side of TRIP steel. Such lamellar formations prevent the austenite from transformation; therefore the retained austenite occurs 
in the microstructure. Besides martensite, also ferrite and both forms of bainite occur in the microstructure of weld metal. The microstructure of H220PD can be characterized as a finegrained ferrite-pearlite structure. Because of heating in resistance spot welding, continual growth of grains towards the weld metal can be observed. A significant growth of pearlite grains occurs in the heat affected zone.

The sample Ag welded with the highest values of welding current $9 \mathrm{kA}$ shows the void and solidification cracks inside the biggest weld nugget. The formation of void in a spot weld is the result of nucleation and growth process during solidification of a liquid nugget after the heat source, i.e. electric current is shut off as was described in (Zhang and Senkara, 2006). The solidification cracking may form under certain condition. The cracks extended from the surface of a weld into its interior with some voids in the nugget. Such cracks may not reduce a joint's strength if they are confined to the centre of the nugget. However, when they extend to the edges of weld nugget they can affect the weld quality.

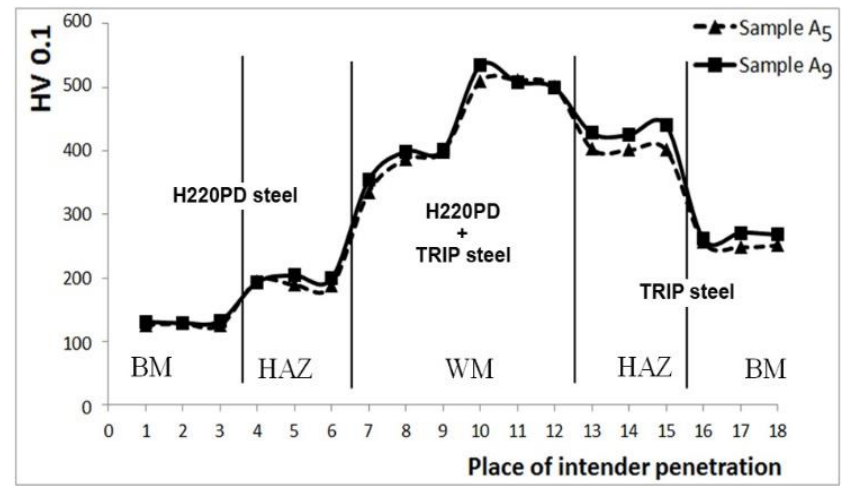

Fig. 7. The values of microstructures of samples $A_{5}$ and $A_{9}$ (BM-base material, HAZ-heat affected zone, WM-weld metal)

The measured values of microhardness are shown in Fig. 7 . The measurements show the changes of the microhardness values in the areas of spot weld. The highest values were measured in the weld metal from TRIP side. The measurements show that increasing the parameters of resistance spot welding does not cause significant microhardness changes in the spot weld.

\section{CONCLUSIONS}

In this study, resistance spot welds of material combination of galvanized AHSS steels sheets and HSLA steels were evaluated.

On the basis of the conducted experiment, the following conclusions can be formed:

Fusion weld joints occur with all chosen parameters of resistance spot welding.

The highest tensile strength was observed in samples made with welding current of $9 \mathrm{kA}$. The average carrying capacity of samples was $7024 \mathrm{~N}$. The lowest values of carrying capacity were observed in samples made with welding current of $5 \mathrm{kA}$, where the average value of carrying capacity decreased by $23 \%$ in comparison to samples A9.

Linear dependence of carrying capacities of spot welds Fmax on welding current I was determined. Increasing values of welding current caused increasing of carrying capacity.
The metallographical analysis confirms that the chosen combination of advanced high strength steels and high strength low alloy steels is suitable for resistance spot welding. On the basis of the results it can be stated, that welding current has a determining influence on the weld joint. When using the welding current of $5 \mathrm{kA}$, weld joint was of high quality, fusible and without defects, but the weld nugget had smaller dimensions in comparison with other weld nuggets made with higher values of welding current. Welding current of $9 \mathrm{kA}$ is not suitable for the examined thickness and sheet combination, because cracking was observed in the heat affected zone of multi-phase material of TRIP.

\section{REFERENCES}

1. Brauser S., Pepke L.A., Weber G., Rethmeier M. (2010), Deformation behaviour of spot-welded high strength steels for automotive appli-cations, Materials Science and Engineering, Vol. 527, 7099-7108.

2. Fernández J., Illescas S., Guilemany J.M. (2007), Effect of microalloying elements on the austenitic grain growth in low carbon HSLA steel, Materials Letters, Vol. 61, 2389-2392.

3. Gorni A.A., Mei P.R. (2004), Austenite transformation and age hardening of HSLA-80 and ULCB steels, Journal of Materials Processing Technology, Vol. 155-156, 1513-1518.

4. Lacroix G., Pardoen T., Jacques P.J. (2008), The fracture toughness of TRIP-assisted multiphase steels, Acta Materialia, Vol. 56, 3711-4124.

5. Ma C., Chen D.L., Bhole S.D., Boudreau G. (2008), Microstructure and fracture characteristics of spot-welded DP600 steel, Materials Science and Engineering, Vol. 485, 334-346.

6. Mucha J., Kaščák L'., Spišák E. (2011), Joining the car-body sheets using clinching process with various thickness and mechanical property arrangements, Archives of civil and mechanical engineering, Vol.11, No. 1, 135-148.

7. Saleh M.H., Priestner R. (2001), Retained austenite in dual-phase silicon steels and its effect on mechanical properties, Journal of Materials Processing Technology, Vol. 113, 587-593.

8. Sevim I. (2006), Effect of hardness to fracture toughness for spot welded steel sheets, Material and Design, Vol. 27, 21-30.

9. Show B.K., Veerababu R., Balamuralikrishnan R., Malakondaiah G. (2010), Effect of vanadium and titanium modification on the microstructure and mechanical properties of a microalloyed HSLA steel, Materials Science and Engineering, Vol. 527, 1595-1604.

10. Sierra R., Nemes J.A. (2008), Investigation of the mechanical behavior of multi-phase TRIP steels using finite element methods, International Journal of Mechanical Sciences, Vol. 50, 649-665.

11. Spišák E., Kaščák L'., Viňáš J. (2011), Research into properties of joints of combined materials made by resistance spot welding, Chemické listy, No. 16, 488-490.

12. Tumuluru M.D. (2006), Resistance spot welding of coated highstrength dualphase steels, Welding Journal, No. 8, 31-37.

13. Vural M., Akkus A. (2004), On the resistance spot weldability of galvanized interstitial free steel sheets with austenitic stainless steel sheets, Journal of Materials Processing Technology, Vol. 153154, 1-6.

14. Williams N.T., Parker J.D. (2004), Modelling and control of weld nugget formation, International Material Review, No. 2, 45-75.

15. Zhang H., Senkara J. (2006), Resistance welding: Fundamentals and Applications, Taylor \& Francis, New York.

Acknowledgment: Authors are grateful for the support of experimental works by project APVV-0682-11: "Application of progressive tool coatings for increasing the effectiveness and productivity of forming sheets made of modern materials". 